\title{
A CONCENTRAÇÃO DE FÓSFORO NA TOLERÂNCIA DE CULTIVARES DE TRIGO À TOXICIDADE DE ALUMINIO EM SOLUÇOES NUTRITIVAS (')
}

\author{
CARLOS EDUARDO DE OLIVEIRA CAMARGO $\left({ }^{2,3}\right)$
}

\section{RESUMO}

Em dois experimentos empregando soluçoes nutritivas, foi estudada a tolerância de cultivares de trigo na presença de $5 \mathrm{mg} /$ litro de $\mathrm{Al}^{3+}$, medida pela capacidade de as raízes primárias continuarem a crescer em solução nutritiva completa sem alumínio, após permanência de $\mathbf{4 8}$ horas em solução contendo alumínio com diferentes concentraçóes de fósforo, controle do $\mathrm{pH}$ e temperatura de $25 \pm 1^{\circ} \mathrm{C}$. No primeiro experimento, foram estudados oito cultivares de trigo em soluçбes nutritivas contendo quatro niveis de fósforo $(0 ; 15,5 ; 31,0$ e $62,0 \mathrm{mg} /$ litro) combinados com três níveis de pH $(4,0 ; 5,0$ e 6,0$)$. Os cultivares CNT-8 e Siete Cerros foram sensíveis e, BH-1146, IAC-18, IAC-13, C-3, IAC-17 e Alondra-4546, tolerantes a 5mg/litro de $\mathrm{Al}^{3+}$ nas soluçoes de tratamento combinado com $0 \mathrm{mg} /$ litro de $\mathrm{P} \mathrm{e} \mathrm{pH}=4,0$. Todos os cultivares foram sensfveis ao $\mathbf{A l}^{3+}$ quando se empregaram $15,5 \mathrm{mg} /$ itro de $\mathrm{P}$ e tolerantes quando se adicionaram $62 \mathrm{mg} /$ litro de $P$, considerando-se fixo o $\mathrm{pH} 4,0$. Com o nível de $31 \mathrm{mg} /$ litro de $\mathrm{P}$, em pH 4,0, os cultivares IAC-18, BH-1146, IAC-13 e C-3 foram tolerantes e 'IAC-17', 'Alondra-4546', 'CNT-8' e 'Siete Cerros', sensíveis. Nas soluçбes com pH 5,0 e 6,0, todos os cultivares foram tolerantes, independente das concentraçסes de $\mathbf{P}$ utilizadas, evidenciando pequena atividade dos fons $\mathrm{Al}^{3+}$ nesses níveis de $\mathrm{pH}$. Os dados demonstraram que a tolerância a $5 \mathrm{mg} / 1$ itro de $\mathrm{Al}^{3+}$, além do $\mathrm{pH}$ da soluçao, foi dependente das concentraçðes de fósforo. No segundo experimento, foram estudados os cultivares BH-1146, IAC-17 e Siete Cerros, em soluçбes de tratamento contendo cinco concentraçбes de $\mathrm{P}(0 ; 1,55 ; 3,875 ; 7,75$ e $15,5 \mathrm{mg} /$ litro) e pH 4,0. Os cultivares BH-1146 e IAC-17 foram tolerantes e, 'Siete Cerros', sensível a $5 \mathrm{mg} / \mathrm{litro}$ de $\mathrm{Al}^{3+}$, quando foram adicionados 0 e $1,55 \mathrm{mg} /$ litro de

( ${ }^{1}$ Com verba suplementar do Acordo do Trigo entre as Cooperativas de Produtores Rurais do Vale do Paranapanema e a Secretaria de Agricultura e Abastecimento, por meio do Instituto Agrondmico. Recebido para publicaçāo em 21 de setembro de 1983.

$\left({ }^{2}\right)$ Seção de Arroz e Cereais de Inverno, Instituto Agronomico (IAC), Caixa Postal 28, $13100-$ Campinas (SP).

$\left({ }^{3}\right)$ Com bolsa de suplementaçăo do CNPq. 
$P$ nas soluçбes de tratamento. Quando se empregaram as concentraçסes de 3,875; 7,75 e $15,5 \mathrm{mg} /$ litro de $P$, todos os cultivares foram sensíveis ao $\mathrm{Al}^{3+}$. Houve aumento mais acentuado nos teores de $P$ na matéria seca das rázes em relação ao das partes aéreas quando se elevaram as concentraçoes de $\mathrm{P}$ das soluçðes. Esse aumento foi mais intenso no 'Siete Cerros' e 'IAC-17' do que no 'BH-1146'. Os teores de Al aumentaram nas raizes para todos os cultivares, à medida que cresceram as concentraçoes de $\mathbf{P}$ das soluções. Os resultados evidenciaram que, com o aumento da concentração de $\mathbf{P}$, acentuou-se o efeito da toxicidade do $\mathrm{Al}^{3+}$, indicando que o $\mathrm{Al}$ e o P ficaram acumulados interna ou externamente nas raízes.

Termos de indexação: alumínio $\mathrm{x}$ fósforo; soluçơes nutritivas; tolerância e sensibilidade à toxicidade de alumínio; cultivares de trigo tolerantes e sensíveis ao Al.

\section{INTRODUÇÃO}

Devido à tendência de o alumínio reagir quimicamente com o fosforo em quase todas as condiçбes (no solo, em soluçסes ou em plantas) com um decréscimo na toxicidade do alumínio ou aparecimento de deficiência de fósforo, a interação alumínio/fósforo resultou em extensas investigaçðes, porém as conclusōes foram tão diversas como os métodos utilizados (ALI, 1973).

RAGLAND \& COLEMAN (1962) mostraram um aumento na absorção de fósforo pelas raízes de feijão-vagem tratadas com alumínio, aumento esse maior quando o fósforo e o alumínio estavam juntos na mesma solução. Esses resultados foram negados por pesquisas feitas por CLARKSON (1966), que sugeriu dois tipos de interação entre $\mathrm{Al}$ e $\mathrm{P}$ : a primeira ocorria na superfície das células e resultava na fixação de $\mathrm{PO}_{4}^{3^{-}}$e, a segunda, dentro das células, resultava em marcante redução na produção de açucares fosforilados.

RASMUSSEN (1968), estudando o modo de entrada, distribuição e localização do $\mathrm{P}$ em plantas de milho, sugeriu que havia uma precipitação do fósforo pelo alumínio, por ter sido a localização do fósforo exatamente a mesma verificada para o Al. Entretanto, uma conclusão oposta foi obtida por WAISEL et alii (1970), estudando a localização do Al em células corticais de feijão e cevada, sem encontrar correlação entre a distribuição de $\mathrm{Al}$ e $P$. Concluiram os autores que fosfatos de aluminio não eram formados na superfície radicular ou dentro das raízes. As diferenças nos resultados poderiam ser explicadas pelo uso de diferentes níveis de $\mathrm{pH}$ nas soluçoes empregadas pelos referidos autores, considerando que, em $\mathrm{pH}$ baixo, o alumínio está na forma catiônica, em $\mathrm{pH}$ próximo à neutralidade, na forma de hidróxido $\mathrm{Al}(\mathrm{OH})_{3}$, e em pH alcalino, na forma aniônica (ALI, 1973).

Esse fato mostrou a necessidade de controle do $\mathrm{pH}$ das soluções nutritivas para o estudo da interação $\mathrm{Al} \times \mathrm{P}$, bem como da toxicidade do $\mathrm{Al}$ às plantas, porém os trabalhos, em sua maioria, não levaram em consideração esse aspecto (ALI, 1973). 
Num estudo envolvendo nove cultivares de trigo em soluçðes nutritivas contendo quatro niveis de $\mathrm{Al}$ tóxico combinados com três níveis de $\mathrm{pH}$ em ausência de fósforo, foi demonstrado que o sintoma de toxicidade do alumínio - paralisação do crescimento radicular - ficou acentuado pelo aumento da concentração de alumínio na solução ou pela diminuição do $\mathrm{pH}$ para todos os cultivares estudados (CAMARGO, 1984). Aparentemente, a tolerância a determinada concentração de alumínio é uma característica antes relativa do que absoluta, por depender da concentração de sais, temperatura e $\mathrm{pH}$ das soluçסes nutritivas em estudo (ALI, 1973; CAMARGO \& OLIVEIRA, 1981; CAMARGO et alii, 1981; CAMARGO, 1983; CAMARGO, 1984).

O presente trabalho tem por objetivo estudar a tolerância de cultivares de trigo a determinado nivel de alumínio em soluçðes nutritivas contendo diferentes concentraçðes de fósforo com controle do $\mathrm{pH}$.

\section{MATERIAL E MÉTODOS}

\section{1 - Experimento n? 1}

Foi realizado em parcelas subdivididas, com duas repetiçбes, com as parcelas compostas de quatro concentraçбes de fósforo $(0 ; 15,5 ; 31,0$ e $62,0 \mathrm{mg} /$ litro) combinadas com três níveis de $\mathrm{pH}(4,0 ; 5,0$ e 6,0$)$ e, as subparcelas formadas por vinte plântulas de oito cultivares de trigo.

Os cultivares de trigo estudados foram os seguintes: BH-1146, IAC18, IAC-13, C-3, IAC-17, Alondra-4546, CNT-8 e Siete Cerros. As sementes foram lavadas com uma solução de hipoclorito de sodio a $10 \%$ e colocadas para germinar em caixas de Petri por 24 horas. Após este tempo, as radículas estavam iniciando a emergência.

Foram escolhidas vinte sementes uniformes de cada cultivar e colocadas sobre a superfície de doze telas de náilon, em cada uma das repetiçðes. Todas as telas contendo as sementes dos oito cultivares foram colocadas em contacto com doze soluçбes nutritivas completas existentes em doze vasilhas plásticas de 8,3 litros de capacidade.

A concentração da solução nutritiva completa foi a seguinte: $\mathrm{Ca}\left(\mathrm{NO}_{3}\right)_{2} \cdot 4 \mathrm{H}_{2} \mathrm{O} 4 \mathrm{mM} ; \quad \mathrm{MgSO}_{4} \cdot 7 \mathrm{H}_{2} \mathrm{O} 2 \mathrm{mM} ; \mathrm{KNO}_{3} 4 \mathrm{mM} ; \quad\left(\mathrm{NH}_{4}\right)_{2} \mathrm{SO}_{4}$ $0,435 \mathrm{mM} ; \quad \mathrm{KH}_{2} \mathrm{PO}_{4} \quad 0,5 \mathrm{mM} ; \quad \mathrm{MnSO}_{4} \cdot 4 \mathrm{H}_{2} \mathrm{O} 2 \mu \mathrm{M} ; \quad \mathrm{CuSO}_{4} \cdot 5 \mathrm{H}_{2} \mathrm{O} \quad 0,3 \mu \mathrm{M}$; $\mathrm{ZnSO}_{4} \cdot 7 \mathrm{H}_{2} \mathrm{O} 0,8 \mu \mathrm{M} ; \mathrm{NaCl} 30 \mu \mathrm{M} ; \mathrm{Fe}-\mathrm{CYDTA} 10 \mu \mathrm{M} ; \mathrm{NaMoO}_{4} \cdot 2 \mathrm{H}_{2} \mathrm{O} 0,10 \mu \mathrm{M}$ e $\mathrm{H}_{3} \mathrm{BO}_{3} \quad 10 \mu \mathrm{M}$. $\mathrm{O}$ nível das soluções nas vasilhas plásticas atingiu a parte de baixo da tela de náilon, de maneira que as sementes foram mantidas úmidas e as radículas emergentes tinham um pronto suprimento de nutrientes. $\mathrm{O} \mathrm{pH}$ da solução foi previamente ajustado para 4,0 com uma solução de 
$\mathrm{H}_{2} \mathrm{SO}_{4} 1 \mathrm{~N}$. As vasilhas plásticas contendo as soluções continuamente arejadas foram colocadas em banho-maria com temperatura de $25 \pm 1^{\circ} \mathrm{C}$, dentro do laboratório. $\mathrm{O}$ experimento foi mantido com luz artificial em sua totalidade.

As plantas desenvolveram-se nessas condiçoes por 48 horas. Após esse período, cada plântula tinha três raízes primárias, uma mais longa, medindo cerca de $4,5 \mathrm{~cm}$, e duas mais curtas, localizadas lateralmente à primeira.

Cada uma das doze telas de náilon contendo vinte plântulas dos oito cultivares foi transferida para doze vasilhas plásticas contendo soluçסes de tratamento com a décima parte da concentração de sais da solução completa, acrescidas de diferentes concentraçoes de fósforo na forma de $\mathrm{KH}_{2} \mathrm{PO}_{4}$ combinadas com três níveis de $\mathrm{pH}$, conforme a relação seguinte:

\begin{tabular}{|c|c|c|}
\hline & $\begin{array}{l}\text { Nivel de P } \\
\text { (mg/litro) }\end{array}$ & $\mathbf{p H}$ \\
\hline $1 \ldots \ldots$ & 0 & 4,0 \\
\hline $2 \ldots \ldots \ldots$ & 15,5 & 4,0 \\
\hline $3 \ldots \ldots \ldots$ & 31,0 & 4,0 \\
\hline $4 \ldots \ldots$ & 62,0 & 4,0 \\
\hline$\ldots$ & 0 & 5,0 \\
\hline $6 \ldots \ldots \ldots$ & 15,5 & 5,0 \\
\hline $7 \ldots \ldots$ & 31,0 & 5,0 \\
\hline $8 \ldots \ldots \ldots$ & 62,0 & 5,0 \\
\hline $9 \ldots \ldots \ldots$ & 0 & 6,0 \\
\hline $10 \ldots \ldots$ & 15,5 & 6,0 \\
\hline $11 \ldots \ldots$ & 31,0 & 6,0 \\
\hline 12 & 62,0 & 6,0 \\
\hline
\end{tabular}

Nas soluçбes de tratamento, o ferro foi adicionado em quantidade equivalente como $\mathrm{FeCl}_{3}$ no lugar do $\mathrm{Fe}$-CYDTA, como foi descrito por MOQORE et alii (1976). Antes da transferência das telas contendo as plântulas para as soluçóes de tratamento, foi adicionada a quantidade necessária de alumínio como $\mathrm{Al}_{2}\left(\mathrm{SO}_{4}\right)_{3} \cdot 18 \mathrm{H}_{2} \mathrm{O}$ para ser obtida a concentração de $5 \mathrm{mg} /$ litro de alumínio. $\mathrm{O} \mathrm{pH}$ final foi ajustado com uma solução de $\mathrm{H}_{2} \mathrm{SO}_{4}$ $1 \mathrm{~N}$ para 4,$0 ; 5,0$ e 6,0 conforme o tratamento.

As plantas após crescerem por 48 horas nas respectivas soluçбes de tratamento, foram transferidas de volta para as vasilhas contendo solução nutritiva completa, onde cresceram nas primeiras 48 horas.

As plântulas permaneceram na solução completa por 72 horas. $\mathrm{O}$ crescimento da raiz nesse perfodo depende da severidade do tratamento com alumínio. Com uma quantidade toxica de alumínio, as raízes primárias não crescem mais e permanecem grossas, mostrando no ápice uma injuria típica 
com descoloramento. A quantidade de crescimento da raiz foi determinada, medindo-se o comprimento da raiz de cada plântula no final das 72 horas na solução nutritiva completa e subtraindo-se o comprimento da mesma raiz no final de crescimento na solução tratamento.

Vinte plântulas dos cultivares BH-1146, IAC-17 e Siete Cerros, submetidas a crescimento em cada uma das doze soluçбes tratamentos, em cada repetição, foram colocadas para secar em estufa a $45^{\circ} \mathrm{C}$ por cinco dias, sendo a seguir analisadas quanto aos teores de $\mathrm{P}, \mathrm{Ca}, \mathrm{Mg}, \mathrm{K}$ e $\mathrm{Al}$, segundo o método de BATAGLIA et alii (1978).

\subsection{Experimento n? 2}

Foi realizado em parcelas subdivididas, com duas repetiçסes, cujas parcelas foram compostas por cinco concentraçōes de fósforo $(0 ; 1,55$; 3,$875 ; 7,75$ e $15,5 \mathrm{mg} /$ litro) nas soluçбes de tratamento, e as subparcelas, por 100 plantas de três cultivares de trigo (BH-1146, IAC-17 e Siete Cerros).

A metodologia empregada foi a mesma descrita no item 2.1, com a diferença que, em todas as vasilhas plásticas contendo soluçoes nutritivas completas e de tratamento, foi utilizado o nível de $\mathrm{pH}=4,0$ e que, após o término do experimento nas soluçðes nutritivas completas, as 100 plântulas de cada cultivar, submetidas a crescimento em cada uma das cinco soluçðes tratamentos, em cada repetição, foram separadas em parte aérea e raízes, para serem analisadas quimicamente.

\section{RESULTADOS E DISCUSSÃO}

\subsection{Experimento n! 1}

O quadro 1 apresenta o comprimento médio das raízes dos oito cultivares de trigo, medido apos 72 horas de crescimento na solução nutritiva completa, seguido de 48 horas de crescimento nas soluçסes de tratamento contendo $5 \mathrm{mg} /$ litro de $\mathrm{Al}^{3+}$, associado a quatro diferentes concentraçðes de fosforo e três níveis de $\mathrm{pH}$.

Considerando as médias dos diferentes cultivares estudados com $0 \mathrm{mg} /$ litro de $\mathbf{P}$ nas soluçðes de tratamento, verificou-se que, quando foi empregado $\mathrm{pH} 4,0$, os cultivares CNT-8 e Siete Cerros foram sensiveis a $5 \mathrm{mg} /$ litro de $\mathrm{Al}^{3+}$, ao passo que os cultivares $\mathrm{BH}-1146, \mathrm{IAC}-18, \mathrm{IAC}-13, \mathrm{C}-3$, IAC-17 e Alondra-4546 foram tolerantes. Nessa mesma concentração de $\mathrm{P}$, mantendo-se, porém, o pH ao nível de 5,0 ou 6,0 , todos os cultivares exibiram crescimento das raízes, evidenciando que, com o aumento do $\mathrm{pH}$, houve 


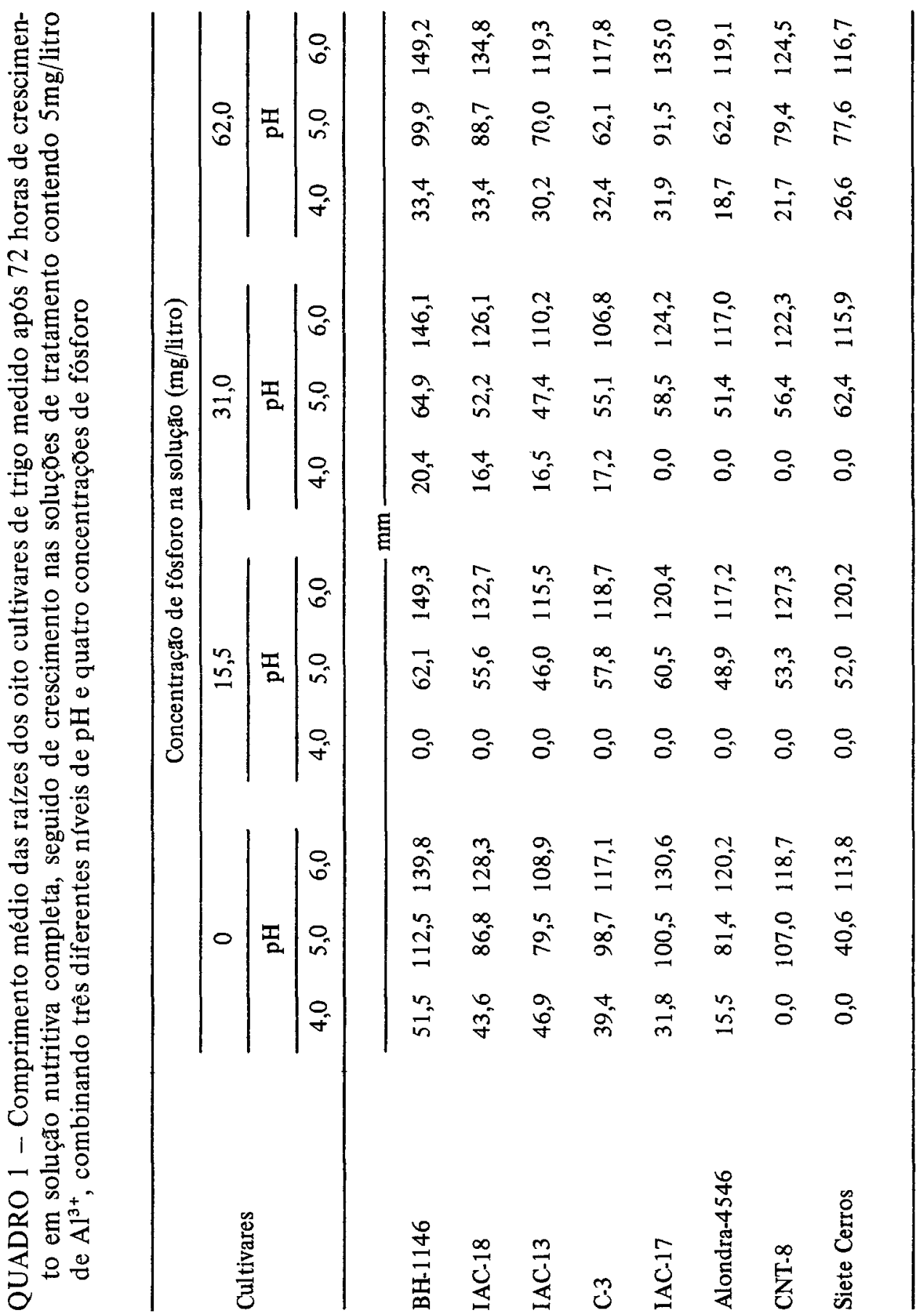


uma conseqüente redução da atividade dos íns $\mathrm{Al}^{3+}$ na solução. Isso também foi observado quando se utilizaram níveis mais elevados de fósforo nas soluções de tratamento.

Considerando as médias de crescimento das raízes quando nas soluçбes de tratamento foram adicionados $15,5 \mathrm{mg} /$ litro de $\mathrm{P}$, mantendo-se $\mathrm{pH}$ 4,0 e $5 \mathrm{mg} /$ litro de $\mathrm{Al}^{3+}$, verificou-se que todos os cultivares foram sensíveis a essa concentração de $\mathrm{Al}^{3+}$, sugerindo uma interação $\mathrm{P}$ x Al que proporcionou maior sensibilidade de todos os cultivares a esse particular tratamento. Com as mesmas concentraçбes de $\mathrm{P}$ e $\mathrm{Al}$ nas soluçðes de tratamento, mantendo-se, porém, o pH nos niveis de 5,0 e 6,0, todos os cultivares apresentaram crescimento das raízes, sendo maior em $\mathrm{pH} 6,0$ do que em $\mathrm{pH} 5,0$.

Quando se adicionaram $31 \mathrm{mg} /$ litro de $P$ nas soluçбes de tratamento, mantendo-se o pH 4,0, os cultivares BH-1146, IAC-1 8, IAC-13 e C-3 foram tolerantes a $5 \mathrm{mg} /$ litro de $\mathrm{Al}^{3+}$, ao passo que os cultivares IAC-17, Alondra-4546, CNT- 8 e Siete Cerros foram sensíveis. No nível de $\mathrm{pH} 4,0$, empregando-se, porém, $62 \mathrm{mg} /$ litro de $\mathrm{P}$ nas soluçoes de tratamento, todos os cultivares foram tolerantes a $5 \mathrm{mg} /$ litro de $\mathrm{Al}^{3+}$.

Com $15,5 \mathrm{mg} /$ litro de $P$ na solução, em presença de $5 \mathrm{mg} /$ litro, houve um aumento do efeito nocivo do $\mathrm{Al}$ às raízes dos cultivares de trigo quando comparado com a solução de tratamento com $\mathrm{pH} 4,0$, onde não foi adicionado $P$, evidenciando que essa concentraça de $P$ provocou um efeito mais nocivo do $\mathrm{Al}$ as raizes do que quando o $\mathrm{P}$ foi omitido. $\grave{A}$ medida que foram aumentados os teores de $P$ das soluçoes para 31 e $62 \mathrm{mg} /$ litro, este fósforo poderia ter precipitado o alumínio das soluçðes, tornando-o incapaz de inibir irreversivelmente o crescimento das raízes, mesmo em pH 4,0.

Estes resultados confirmaram o trabalho de MOORE et alii (1976), que sugeriram a omissão do fósforo das soluçōes de tratamento contendo $\mathrm{Al}^{3+}$, visando evitar a possível precipitação desse elemento como $\mathrm{Al}(\mathrm{OH})_{3}$, mesmo em $\mathrm{pH}=4,0$. Foram também confirmados os resultados obtidos por CAMARGO (1984), para quem a identificação de cultivares de trigo tolerantes e sensíveis ao $\mathrm{Al}^{3+}$, em soluçoes nutritivas, foi significativamente dependente do $\mathrm{pH}$ da solução e conseqüentemente, da atividade do íon $\mathrm{Al}^{3+}$ na solução.

Os dados obtidos nesse experimento também demonstraram que a reação dos cultivares de trigo a uma particular concentração de $\mathrm{Al}^{3+}$, além do $\mathrm{pH}$ da solução foi dependente das quantidades adicionadas de fósforo.

Os teores médios de $\mathrm{P}, \mathrm{Ca}, \mathrm{Mg}, \mathrm{K}$ e $\mathrm{Al}$ na matéria seca total das vinte plântulas dos cultivares BH-1146, IAC-17 e Siete Cerros, submetidas a crescimento em doze soluçðes de tratamento, no experimento n? 1 , encontram-se no quadro 2 e figuras 1 e 2 . 


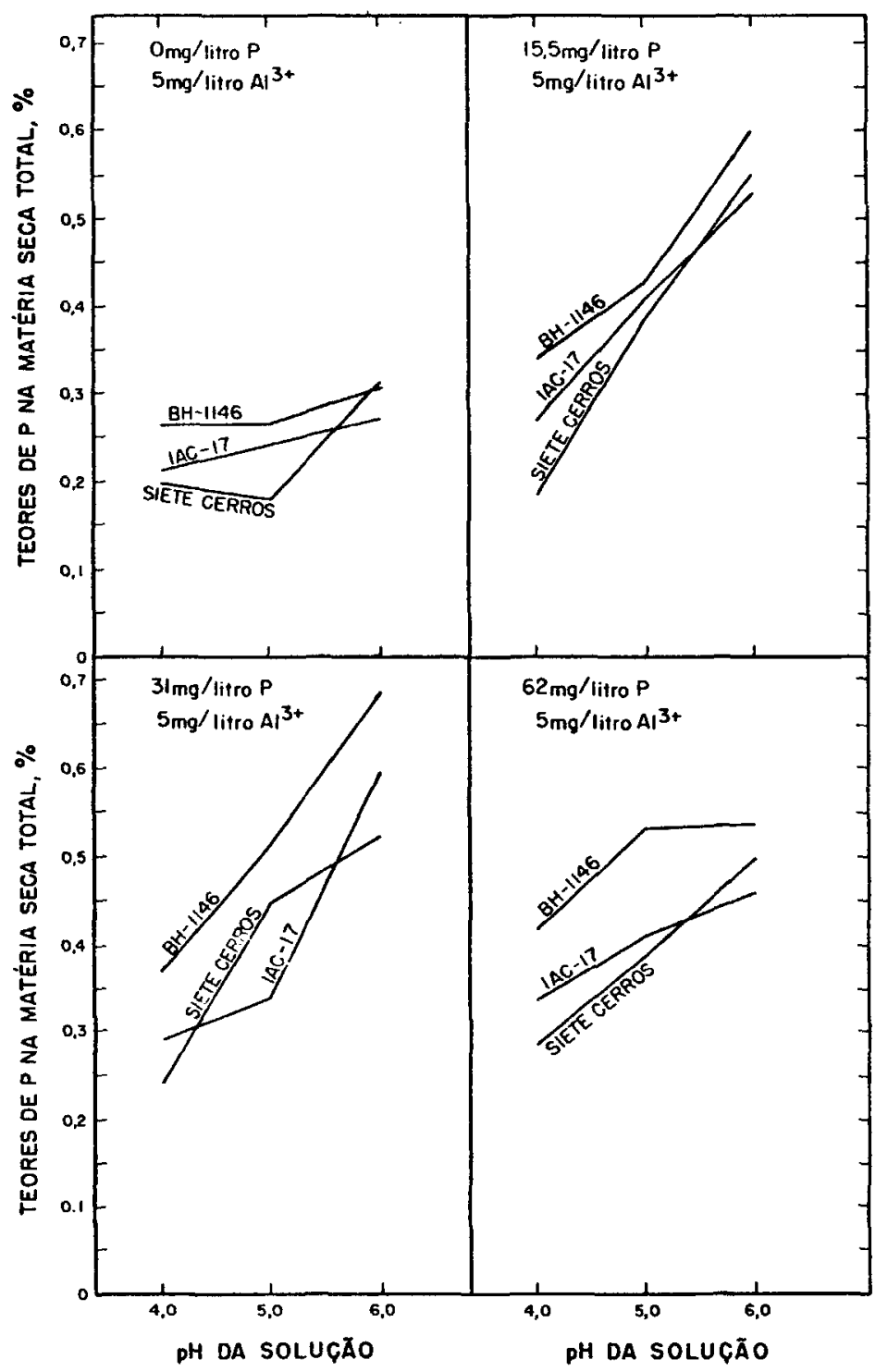

FIGURA 1 - Teores de P na matéria seca total de três cultivares de trigo estudados em soluçōes nutritivas contendo $5 \mathrm{mg} /$ litro de $\mathrm{Al}^{3+}$ combinando três n ńveis de $\mathrm{pH}$ e quatro concentraçoes de fósforo. 


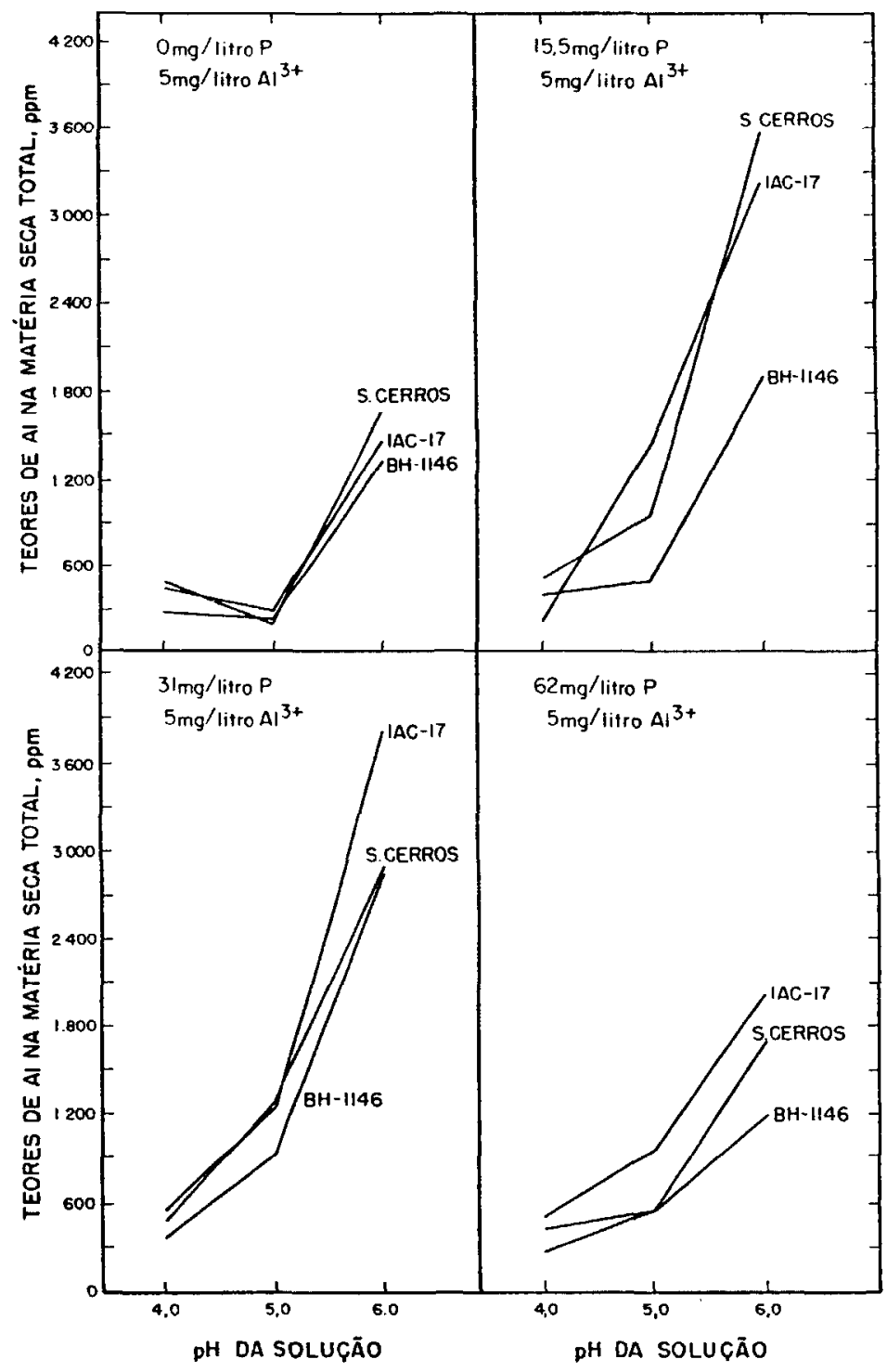

FIGURA 2 - Teores de Al na parte aérea de três cultivares de trigo estudados em soluçôes nutritivas contendo $5 \mathrm{mg} / \mathrm{litro}$ de $\mathrm{Al}^{3+}$, combinando três níveis de $\mathrm{pH}$ e quatro concentraçóes de fósforo. 
QUADRO 2 - Teores médios de fósforo, potássio, cálcio, magnésio e alumínio de três cultivares de trigo estudados em soluçôes nutritivas contendo $5 \mathrm{mg} /$ litro de $\mathrm{Al}^{3+}$ combinando três níveis de $\mathrm{pH}$ e quatro concentraçбes de fósforo

\begin{tabular}{|c|c|c|c|c|c|c|c|}
\hline \multirow{2}{*}{ Cultivares } & \multicolumn{2}{|c|}{ Solução tratamento } & \multicolumn{5}{|c|}{ Teores de elementos na matéria seca total } \\
\hline & $\mathbf{P}$ & $\mathrm{pH}$ & $\mathbf{P}$ & $\mathrm{Ca}$ & $\mathrm{Mg}$ & $\mathbf{K}$ & $\mathrm{Al}$ \\
\hline & \multicolumn{2}{|c|}{$\mathrm{mg} / \mathrm{litro}$} & \multicolumn{4}{|c|}{$-\%$} & ppm \\
\hline \multirow[t]{4}{*}{ BH-1146 } & 0 & $\begin{array}{l}4,0 \\
5,0 \\
6,0\end{array}$ & $\begin{array}{l}0,264 \\
0,266 \\
0,307\end{array}$ & $\begin{array}{l}0,32 \\
0,34 \\
0,31\end{array}$ & $\begin{array}{l}0,29 \\
0,29 \\
0,29\end{array}$ & $\begin{array}{l}6,29 \\
6,05 \\
6,86\end{array}$ & $\begin{array}{r}280 \\
223 \\
1315\end{array}$ \\
\hline & 15,5 & $\begin{array}{l}4,0 \\
5,0 \\
6,0\end{array}$ & $\begin{array}{l}0,343 \\
0,433 \\
0,606\end{array}$ & $\begin{array}{l}0,33 \\
0,33 \\
0,35\end{array}$ & $\begin{array}{l}0,29 \\
0,30 \\
0,32\end{array}$ & $\begin{array}{l}6,31 \\
7,04 \\
6,90\end{array}$ & $\begin{array}{r}394 \\
486 \\
1844\end{array}$ \\
\hline & 31,0 & $\begin{array}{l}4,0 \\
5,0 \\
6,0\end{array}$ & $\begin{array}{l}0,371 \\
0,517 \\
0,686\end{array}$ & $\begin{array}{l}0,32 \\
0,33 \\
0,37\end{array}$ & $\begin{array}{l}0,30 \\
0,30 \\
0,29\end{array}$ & $\begin{array}{l}6,30 \\
6,99 \\
7,29\end{array}$ & $\begin{array}{r}363 \\
938 \\
2829\end{array}$ \\
\hline & 62,0 & $\begin{array}{l}4,0 \\
5,0 \\
6,0\end{array}$ & $\begin{array}{l}0,418 \\
0,534 \\
0,538\end{array}$ & $\begin{array}{l}0,30 \\
0,32 \\
0,33\end{array}$ & $\begin{array}{l}0,28 \\
0,29 \\
0,30\end{array}$ & $\begin{array}{l}6,36 \\
6,88 \\
7,00\end{array}$ & $\begin{array}{r}275 \\
562 \\
1209\end{array}$ \\
\hline \multirow[t]{4}{*}{ IAC-17 } & 0 & $\begin{array}{l}4,0 \\
5,0 \\
6,0\end{array}$ & $\begin{array}{l}0,212 \\
0,242 \\
0,272\end{array}$ & $\begin{array}{l}0,29 \\
0,27 \\
0,31\end{array}$ & $\begin{array}{l}0,27 \\
0,25 \\
0,27\end{array}$ & $\begin{array}{l}5,90 \\
5,88 \\
6,36\end{array}$ & $\begin{array}{r}434 \\
277 \\
1449\end{array}$ \\
\hline & 15,5 & $\begin{array}{l}4,0 \\
5,0 \\
6,0\end{array}$ & $\begin{array}{l}0,272 \\
0,414 \\
0,534\end{array}$ & $\begin{array}{l}0,31 \\
0,32 \\
0,35\end{array}$ & $\begin{array}{l}0,27 \\
0,28 \\
0,30\end{array}$ & $\begin{array}{l}6,23 \\
6,36 \\
6,51\end{array}$ & $\begin{array}{r}200 \\
1423 \\
3202\end{array}$ \\
\hline & 31,0 & $\begin{array}{l}4,0 \\
5,0 \\
6,0\end{array}$ & $\begin{array}{l}0,290 \\
0,337 \\
0,596\end{array}$ & $\begin{array}{l}0,30 \\
0,30 \\
0,37\end{array}$ & $\begin{array}{l}0,26 \\
0,27 \\
0,28\end{array}$ & $\begin{array}{l}5,77 \\
6,26 \\
6,74\end{array}$ & $\begin{array}{r}544 \\
1234 \\
3801\end{array}$ \\
\hline & 62,0 & $\begin{array}{l}4,0 \\
5,0 \\
6,0\end{array}$ & $\begin{array}{l}0,336 \\
0,412 \\
0,461\end{array}$ & $\begin{array}{l}0,27 \\
0,30 \\
0,34\end{array}$ & $\begin{array}{l}0,25 \\
0,26 \\
0,28\end{array}$ & $\begin{array}{l}5,92 \\
6,41 \\
6,03\end{array}$ & $\begin{array}{r}351 \\
961 \\
1994\end{array}$ \\
\hline \multirow[t]{4}{*}{ Siete Cerros } & 0 & $\begin{array}{l}4,0 \\
5,0 \\
6,0\end{array}$ & $\begin{array}{l}0,198 \\
0,180 \\
0,309\end{array}$ & $\begin{array}{l}0,27 \\
0,26 \\
0,36\end{array}$ & $\begin{array}{l}0,27 \\
0,27 \\
0,28\end{array}$ & $\begin{array}{l}3,92 \\
4,23 \\
5,25\end{array}$ & $\begin{array}{r}483 \\
181 \\
1621\end{array}$ \\
\hline & 15,5 & $\begin{array}{l}4,0 \\
5,0 \\
6,0\end{array}$ & $\begin{array}{l}0,186 \\
0,394 \\
0,560\end{array}$ & $\begin{array}{l}0,33 \\
0,26 \\
0,41\end{array}$ & $\begin{array}{l}0,28 \\
0,27 \\
0,30\end{array}$ & $\begin{array}{l}4,38 \\
5,46 \\
5,79\end{array}$ & $\begin{array}{r}490 \\
941 \\
3516\end{array}$ \\
\hline & 31,0 & $\begin{array}{l}4,0 \\
5,0 \\
6,0\end{array}$ & $\begin{array}{l}0,241 \\
0,450 \\
0,525\end{array}$ & $\begin{array}{l}0,30 \\
0,28 \\
0,35\end{array}$ & $\begin{array}{l}0,27 \\
0,27 \\
0,29\end{array}$ & $\begin{array}{l}4,08 \\
5,22 \\
5,73\end{array}$ & $\begin{array}{r}464 \\
1264 \\
2869\end{array}$ \\
\hline & 62,0 & $\begin{array}{l}4,0 \\
5,0 \\
6,0\end{array}$ & $\begin{array}{l}0,287 \\
0,390 \\
0,504\end{array}$ & $\begin{array}{l}0,30 \\
0,28 \\
0,32\end{array}$ & $\begin{array}{l}0,28 \\
0,28 \\
0,29\end{array}$ & $\begin{array}{l}4,16 \\
5,54 \\
5,69\end{array}$ & $\begin{array}{r}441 \\
561 \\
1674\end{array}$ \\
\hline
\end{tabular}


Pelos resultados, verifica-se para os três cultivares, que, à proporção que se aumentou o $\mathrm{pH}$ de 4,0 para 6,0, mantendo-se constante uma particular concentração de $P$ na solução, houve um aumento na absorção de fósforo. $\mathrm{O}$ ' $\mathrm{BH}-1146$ ', tolerante ao $\mathrm{Al}^{3+}$, em todos os tratamentos, apresentou os maiores teores de P na matéria seca total, em comparação com 'IAC17 ' e 'Siete Cerros'.

Considerando uma particular concentração de $P$ nas soluçðes contendo $5 \mathrm{mg} /$ litro de $\mathrm{Al}^{3+}$, para os três cultivares considerados, houve aumento nos teores de $\mathrm{Al}$ na matéria seca total, quando o $\mathrm{pH}$ das soluçбes aumentou de 4,0 para 6,0, sem prejuízo para o crescimento das raízes. Os resultados sugeriram que grande parte do alumínio não foi absorvido pelas plantas, mas ficou acumulado, interna ou externamente nas rafzes, de forma inativa, conforme trabalho desenvolvido por CLARKSON (1966).

Houve um aumento nos teores de $\mathrm{Al}$ na matéria seca total conforme se elevaram as concentraçðes de fósforo das soluçðes de tratamento de 0 para $31 \mathrm{mg} /$ litro; à medida, porém, que se aumentaram os teores de fósforo de 31 para $62 \mathrm{mg} /$ litro, houve marcante reduçao nos teores de $\mathrm{Al}$ na matéria seca total, independente do $\mathrm{pH}$ considerado.

Em todos os tratamentos, o cultivar $\mathrm{BH}-1146$ foi o mais tolerante ao $\mathrm{Al}^{3+}$ presente nas soluçбes, apresentando as menores quantidades de $\mathrm{Al}$ na matéria seca total.

\subsection{Experimento n? 2}

O comprimento médio das raízes dos três cultivares de trigo, medido após 72 horas de crescimento na solução nutritiva completa, seguido de 48 horas de crescimento nas soluçoes de tratamento contendo $5 \mathrm{mg} / \mathrm{litro}$ de $\mathrm{Al}^{3+}$ e cinco diferentes concentraçōes de fósforo, encontram-se no quadro 3 .

Pelas suas médias, os cultivares BH-1146 e IAC-17, quando estudados em soluçðes de tratamento contendo 0 e $1,55 \mathrm{mg} /$ litro de $P$, apresentaram crescimento radicular. Nessas mesmas condiçбes, o 'Siete Cerros' mostrou-se sensivel ao $\mathrm{Al}^{3+}$, apresentando raízes com o ápice descolorido e, portanto, sem crescimento radicular.

Quando se adicionaram 3,$875 ; 7,75$ e $15,5 \mathrm{mg} /$ litro nas soluçனes em

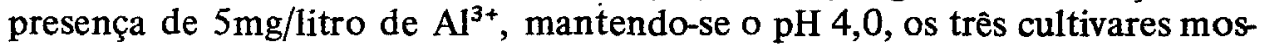
traram-se sensíveis ao $\mathrm{Al}^{3+}$. Esses dados confirmaram aqueles obtidos no experimento no 1, particularmente quando foi empregada a concentração de $15,5 \mathrm{mg} /$ litro de fósforo.

Os teores médios de $\mathrm{P}, \mathrm{Ca}, \mathrm{Mg}, \mathrm{K}$ e $\mathrm{Al}$ na matéria seca das partes aéreas e das raízes das 100 plântulas dos cultivares BH-1 146, IAC-17 e Siete 
Cerros, submetidos a crescimento em cinco soluçбes de tratamento, com duas repetiçбes, encontram-se no quadro 4 . Na figura 3 estão representados os teores de $\mathbf{P}$ e de $\mathrm{Al}$ nas partes aéreas e raizes dos cultivares estudados em função da concentração de $\mathrm{P}$ nas soluçбes de tratamento, contendo $5 \mathrm{mg} /$ litro $\operatorname{de~} \mathrm{Al}^{3+}$, em $\mathrm{pH}=4,0$.

QUADRO 3 - Comprimento médio das raízes de três cultivares de trigo medido apos 72 horas de crescimento em solução nutritiva completa seguido de crescimento nas soluçסes de tratamento contendo $5 \mathrm{mg} /$ litro de $\mathrm{Al}^{3+}$ combinando cinco concentraçores de fósforo

\begin{tabular}{lrrrrr}
\hline \multirow{2}{*}{ Cultivares } & \multicolumn{5}{c}{ Concentração de fósforo na solução (mg/litro) } \\
\cline { 2 - 6 } & 0 & 1,55 & 3,875 & 7,75 & 15,5 \\
\hline & & & mm & & \\
BH-1146 & 35,4 & 25,9 & 0,0 & 0,0 & 0,0 \\
IAC-17 & 10,6 & 6,2 & 0,0 & 0,0 & 0,0 \\
Siete Cerros & 0,0 & 0,0 & 0,0 & 0,0 & 0,0 \\
\hline
\end{tabular}

Os resultados mostraram que, conforme se elevaram as concentrações de fósforo nas soluções de tratamento em presença de $\mathrm{Al}$, houve aumento nos teores de fósforo na matéria seca da parte aérea e das rázes para os cultivares IAC-17 e Siete Cerros, mais acentuado nas raízes. $O$ aumento nos teores de fósforo na matéria seca da parte aérea e das raízes no ' $\mathrm{BH}-1146$ ' foi menos acentuado do que nos outros dois cultivares estudados.

Os teores de alumínio nas rafzes aumentaram para todos os cultivares à medida que cresceram as concentraçбes de fosforo nas soluçðes tratamento, porém 'BH-1146' exibiu menores teores em relaçăo a 'IAC-17' e 'Siete Cerros'. Não houve variaçбes consistentes nos teores de $\mathrm{Al}$ na matéria seca da parte aérea conforme se elevaram os níveis de $P$ nas soluçoes. Os dados mostraram que, a partir da concentração de $3,875 \mathrm{mg} /$ litro de $\mathbf{P}$ nas soluçסes, quando todos os cultivares não apresentaram crescimento radicular, isto é, foram sensíveis ao $\mathrm{Al}^{3+}$, a maior parte do $\mathrm{Al}$ ficou acumulado nas raizes, interna ou externamente, juntamente com o fósforo, confirmando o trabalho de CLARKSON (1966).

$\mathrm{O}$ aumento da concentração de fósforo nas soluções de tratamento de 0 para $15,5 \mathrm{mg}$ /litro em presença de $5 \mathrm{mg} /$ litro de $\mathrm{Al}^{3+}, \mathrm{pH}=4,0$ e temperatura de $25 \pm 1^{\circ} \mathrm{C}$ tornou mais acentuado o efeito da toxicidade de $\mathrm{Al}^{3+}$ para os três cultivares, confirmando os resultados do experimento $n$ ? 1 . 


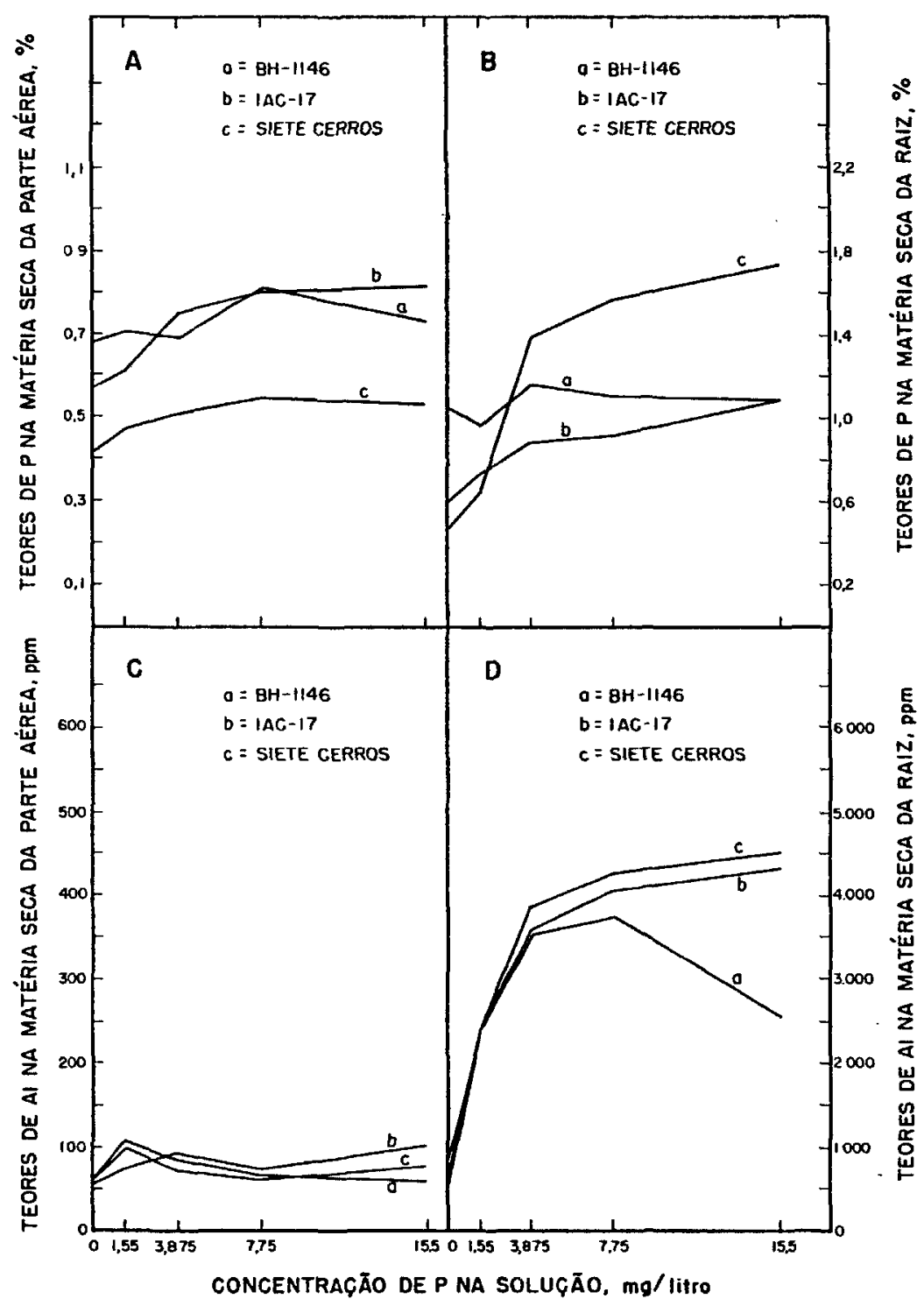

FIGURA 3 - Efeito de cinco concentraçбes de fosforo em soluçoes nutritivas, com $\mathrm{pH}$ 4,0, contendo $5 \mathrm{mg} / \mathrm{litro}$ de $\mathrm{Al}^{3+}$, nos teores de $\mathrm{P}$ : A: matéria seca da parte aérea e B: das raízes, e nos teores de $\mathrm{Al}, \mathrm{C}$ : matéria seca da parte aérea e $\mathrm{D}$ : das raízes, nos cultivares de trigo BH-1 146, IAC- 17 e Siete Cerros. 


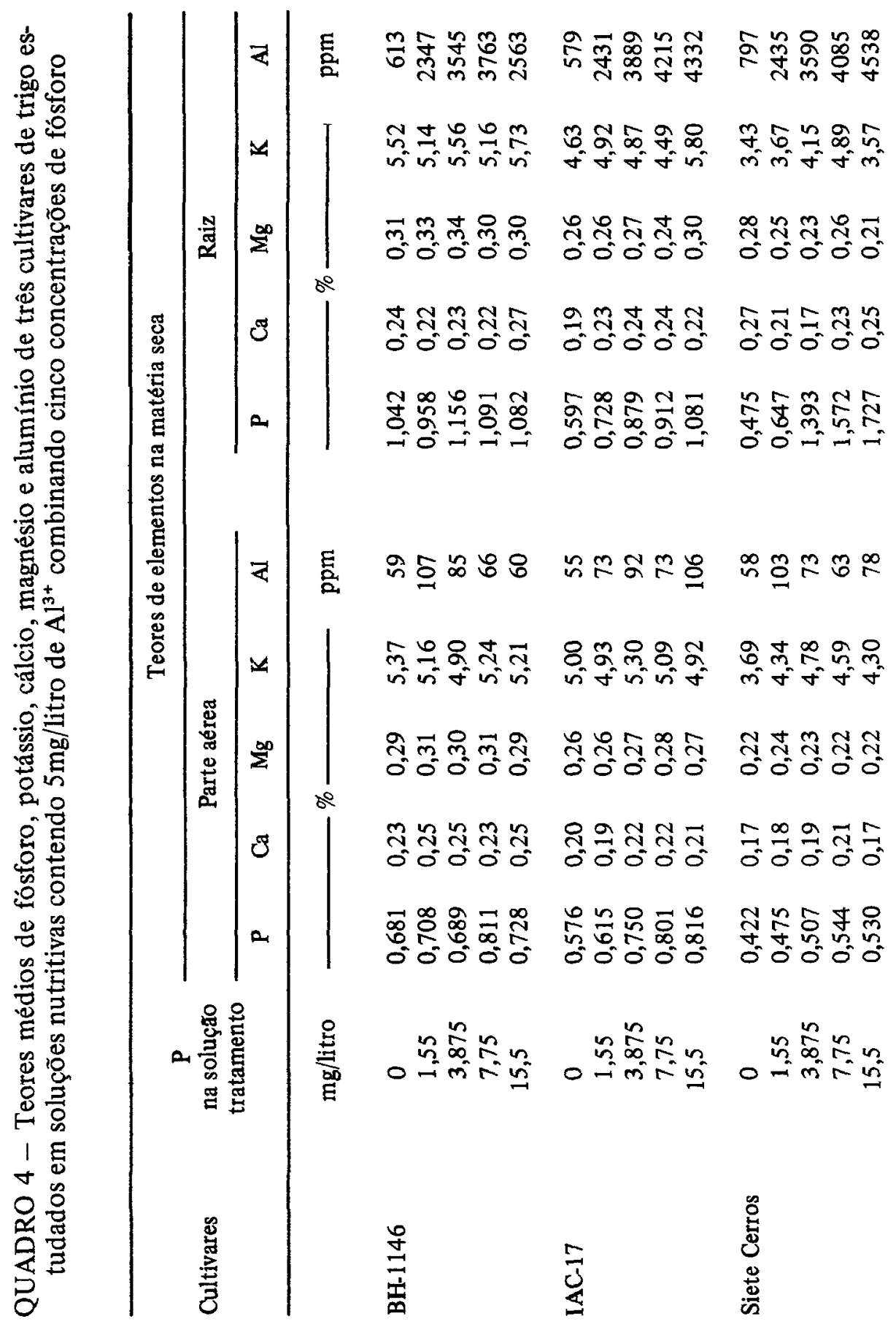




\section{SUMMARY}

\section{EFFECT OF PHOSPHORUS IN NUTRIENT SOLUTION ON THE TOLERANCE TO ALUMINUM TOXICITY IN WHEAT CULTIVARS}

Two experiments were conducted with the objective of studying the tolerance of wheat cultivars to $5 \mathrm{mg} / \ell$ of $\mathrm{Al}^{3+}$ in nutrient solutions. The tolerance was evaluated by measuring the root growth in an aluminum-free complete nutrient solution after a treatment of 48 hours, in aluminum solution with different levels of phosphorus, and with controlled $\mathrm{pH}$ and temperature $\left(25 \pm 1^{\circ} \mathrm{C}\right)$. In the first experiment eight cultivars were studied in treatment solutions with four levels of phosphorus $(0 ; 15.5 ; 31.0$ and $62.0 \mathrm{mg} / \chi$ combined with three levels of $\mathrm{pH}(4.0 ; 5.0$ and 6.0). The cultivars CNT-8 and Siete Cerros were sensitive and 'BH-1146', 'IAC18', 'IAC-13', 'C-3', 'IAC-17' and 'Alondra-4546' were tolerant to $5 \mathrm{mg} / \ell$ of $\mathrm{Al}^{3+}$ in the solutions with pH 4.0 and in absence of $P$. All cultivars were sensitive to $\mathrm{Al}^{3+}$ when it was applied $15.5 \mathrm{mg} / \ell$ of $P$ and they were tolerant when was used $62 \mathrm{mg} / \ell$ of $P$ in the solutions, considering constant the $\mathrm{pH} 4.0$. In solutions with the level of $31 \mathrm{mg} / \mathrm{l}$ of $\mathrm{P}$ and $\mathrm{pH} 4.0$, the cultivars $\mathrm{IAC}-18, \mathrm{BH}-1146, \mathrm{IAC}-13$ and $\mathrm{C}-3$ showed tolerance and IAC-17, Alondra-4546, CNT-8 and.Siete Cerros showed sensitivity to $\mathrm{Al}^{\mathrm{Ht}}$. When it was used solution with $\mathrm{pH} 5.0$ or 6.0 the cultivars presented tolerance, being non dependent of $P$ concentration, in consequence of the low activity of $\mathrm{Al}^{3+}$ ions under these $\mathrm{pH}$ levels. The data demonstrated that tolerance to $5 \mathrm{mg} / \ell$ of $\mathrm{Al}^{3+}$, besides the $\mathrm{pH}$ level was dependent on the $\mathrm{P}$ concentration in the solution. The cultivars BH-1146, IAC-17 and Siete Cerros were studied in a second experiment in nutrient solutions with $\mathrm{pH} 4.0$, containing five $\mathrm{P}$ concentrations $(0 ; 1.55 ; 3.875 ; 7.75$ and $15.5 \mathrm{mg} / \mathrm{\ell}$ ). 'BH-1146' and 'IAC-17' were tolerant and 'Siete Cerros' was sensitive to $5 \mathrm{mg} / \mathrm{l}$ of $\mathrm{Al}^{3+}$ when it was added 0 and $1.55 \mathrm{mg} / \mathrm{l}$ of $\mathrm{P}$ into the treatment solution. When it was considered the $P$ levels of $3.875 ; 7.75$ and $15.5 \mathrm{mg} / \ell$ all cultivars showed symptoms of Al toxicity in their roots. There was an increase in $P$ content in aereal part and root dry matter with the increasing amount of $P$ into the solutions, being more evident in 'IAC-17' and 'Siete Cerros' than in 'BH-1146'. Aluminum content in root dry matter increased in all cultivars as the $P$ concentration increased into the solutions, suggesting that $\mathrm{Al}$ and $\mathrm{P}$ became accumulated in the roots, external or internally.

Index terms: aluminum $x$ phosphorus interaction; nutrient solutions; tolerance to $\mathrm{Al}$ toxicity; sensitivity to Al toxicity; wheat cultivars tolerant to $\mathrm{Al}$; wheat cultivars sensitive to $\mathrm{Al}$.

\section{REFERÊNCIAS BIBLIOGRÁFICAS}

ALI, M.S. Influence of cations on aluminum toxicity in wheat (Triticum aestivum Vill., Host). Corvallis, Oregon State University, 1973. 102f. Tese. (Doutoramento)

BATAGLIA, O.C.; TEIXEIRA, J.P.F.; FURLANI, P.R.; FURLANI, A.M.C. \& GALLO, J.R. Métodos de análise química de plantas. Campinas, Instituto Agronômico, 1978. 31p. (Circular, 87)

CAMARGO, C.E.O. $\mathrm{O}$ pH das soluçðes nutritivas no comportamento de cultivares de trigo à toxicidade de alumínio. Bragantia, Campinas, 43(2): 327-335, 1984. 
CAMARGO, C.E.O. Efeito da temperatura da solução nutritiva na tolerância ao alumínio de cultivares de trigo. Bragantia, Campinas, 42: 51-63, 1983.

\& OLIVEIRA, O.F. Tolerância de cultivares de trigo a diferentes níveis de alumínio em solução nutritiva e no solo. Bragantia, Campinas, 40: $21-31,1981$.

\& LAVORENTI, A. Efeito de diferentes concentraçðes de sais em solução nutritiva na tolerância de cultivares de trigo à toxicidade de alumínio. Bragantia, Campinas, 40: 93-101, 1981.

CLARKSON, D.T. Effect of aluminum on the uptake and metabolism of phosphorus by barley seedlings. Plant Physiology, 41:165-172, 1966.

MOORE, D.P.; KRONSTAD, W.E. \& METZGER, R. Screening wheat for aluminum tolerance. In: WORKSHOP ON PLANT ADAPTATION TO MINERAL STRESS IN PROBLEM SOILS, Beltsville, Maryland, 1976, edited by Madison J. Wright - Proceedings. Ithaca, Cornell University, 1976. p. 287-295.

RAGLAND, J.L. \& COLEMAN, N.T. Influence of aluminum on phosphorus uptake by snap bean roots. Soil Science Society of America Proceedings, 26:88-90, 1962.

RASMUSSEN, H.P. Entry and distribution of aluminum in Zea mays: electron microprobe X-ray analysis. Planta, 81:28-37, 1968.

WAISEL, Y.; HOFFEN, A. \& ESHEL, A. The localization of aluminum in cortex cells of bean and barley roots by x-ray micro-analysis. Physiologia Plantarum, 23:75-79, 1970. 